\title{
Mounier-Kühn syndrome
}

INSERM

\section{Source}

INSERM. (1999). Orphanet: an online rare disease and orphan drug data base. MounierKühn syndrome. ORPHA:3347

Mounier-Kühn syndrome, also known as idiopathic tracheobronchomegaly, is a congenital disorder characterized by marked dilatation of the trachea and proximal bronchi that leads to impaired airway secretion clearance and recurrent lower respiratory tract infections. 